\title{
The use of 16S ribosomal RNA analyses to investigate the phylogeny of the family Legionellaceae
}

\author{
Norman K. Fry,${ }^{1}$ Simon Warwick, ${ }^{2}$ Nicholas A. Saunders ${ }^{1}$ and T. Martin Embley ${ }^{2 *}$ \\ ${ }^{1}$ Molecular Biology Unit, DMRQC, 61 Colindale Avenue, London NW9 5HT, UK \\ ${ }^{2}$ Microbial Technology Research Unit, Polytechnic of East London, Romford Road, London E15 4LZ, UK
}

(Received 10 October 1990; revised 7 January 1991; accepted 16 January 1991)

\begin{abstract}
The 16S ribosomal RNA sequences of Legionella pneumophila, L. erythra, L. hackeliae, $L$. spiritensis, $L$. longbeachae, L. bozemanii (Fluoribacter bozemanae) and L. micdadei (Tatlockia micdadei) were determined using reverse transcriptase. The sequences were compared with published sequences for Gram-negative bacteria and phylogenetic trees were constructed. The data confirm previous work which showed that the family Legionellaceae forms a monophyletic subgroup within the gamma subdivision of the Proteobacteria. The data show that all of the legionellae studied are highly related ( $>95 \%$ ) on the basis of $16 \mathrm{~S}$ rRNA sequences and do not support the division of the family Legionellaceae into three genera.
\end{abstract}

\section{Introduction}

The family Legionellaceae was initially proposed for a single genus Legionella and species L. pneumophila, the causal agent of Legionnaires' disease (Brenner et al., 1979). Subsequently large numbers of new species of Legionella have been isolated from clinical and environmental samples (Brenner, 1986; Brenner et al., 1985, 1988). All of these isolates share a common set of phenotypic characteristics that include a non-fermentative metabolism, the requirement for L-cysteine and iron salts for growth, ubiquinones with 10 or more isoprene units, and predominantly branched-chain cellular fatty acids (Karr et al., 1982; Brenner et al., 1984; Brenner, 1986). The identification of legionellae at the species level is more difficult as there are relatively few suitable phenotypic tests (Brenner, 1986; Brenner et al., 1984; Fox et al., 1984, 1990; Vesey et al., 1988). New species are identified by DNA pairing measurements, and this method is the only means by which some species may be distinguished (Brenner, 1986; Brenner et al., 1988). However, DNA pairing values between species within the genus Legionella may vary between $0 \%$ and $67 \%$ under optimum reassociation conditions (Garrity et al., 1980; Brown et al., 1981; Brenner, 1986). The very low DNA hybridization values that are obtained between some species of Legionella have been interpreted differently. One group (Garrity et al., 1980; Brown et al., 1981) has advocated that the family Legionellaceae be subdivided into three genera. The genus Fluoribacter was proposed for strains of Legionella bozemanii which exhibit blue-white autofluorescence and show less than $14 \%$ DNA relatedness to $L$. pneumophila (Garrity et al., 1980; Brown et al., 1981). A further genus, Tatlockia, was proposed for L. micdadei (Hébert et al., 1980b), which shows less than $5 \%$ DNA relatedness to L. pneumophila (Garrity et al., 1980; Brown et al., 1981). In contrast to these proposals, others have argued that all legionellae are sufficiently similar and unusual in phenotype to be classified in a single genus (Brenner et al., 1980, 1984; Hébert et al., 1980a,b; Morris et al., 1980; Brenner, 1986). At present there is no clear agreement as to which position is correct and the same strains appear in the Approved Lists of Bacterial Names under two different names.

The sequence of the genes that code for ribosomal RNA (rRNA) are among the most highly conserved yet identified (Brenner, 1986; Woese, 1987). Consequently they can be used to determine taxonomic relationships between species which show little DNA interrelatedness (Brenner, 1986). The accuracy of phylogenetic inferences from rRNA sequences depends upon the number of bases compared, and to be fully effective at least 1000 bases should be considered for each organism (Murray $e t$ al., 1990). Ludwig \& Stackebrandt (1983) investigated the phylogeny of Legionella pneumophila, Legionella bozemanii ( $F$. bozemanae) and Legionella micdadei ( $T$. micdadei) using oligonucleotide cataloguing of $16 \mathrm{~S}$ rRNA, which recovers about $40 \%$ of the $16 \mathrm{~S}$ rRNA sequence. The results of that study showed that all three 
organisms were related and well separated from other Gram-negative bacteria but did not resolve whether there should be one or three genera. Fox \& Brown (1989) used reverse transcriptase to sequence short stretches (350-450 bases) of 16S rRNA from three strains of $L$. pneumophila and three of $L$. micdadei ( $T$. micdadei). However, they were unable to draw any conclusions about the taxonomic structure of the family Legionellaceae. In the current investigation we have attempted to determine the detailed relationships of the family Legionellaceae by sequencing long stretches (about 95\%) of the 16S rRNA from a representative sample of species including L. pneumophila, L. erythra, L. hackeliae, $L$. spiritensis, L. longbeachae, L. bozemanii ( $F$. bozemanae) and $L$. micdadei (T. micdadei).

\section{Methods}

Bacterial strains and cultivation. The test strains (Table 1) were inoculated onto buffered charcoal yeast-extract agar (BCYE) and incubated for $48 \mathrm{~h}$ at $37^{\circ} \mathrm{C}$. The cells were removed from the surface of the plates using sterile saline $(0.85 \%, \mathrm{w} / \mathrm{v})$, pelleted by centrifugation at $10000 \mathrm{~g}$, and stored at $-70^{\circ} \mathrm{C}$.

Isolation of RNA. The method used was modified from that described by Saunders \& Grant (1984). Approximately $2 \mathrm{~g}$ wet weight of cells was resuspended in $5 \mathrm{ml}$ of a buffer containing $25 \%(\mathrm{w} / \mathrm{v})$ sucrose, $50 \mathrm{~mm}$ Tris/ $\mathrm{HCl}\left(\mathrm{pH} 8.0\right.$ ) and $3.3 \mathrm{mg}$ lysozyme $\mathrm{ml}^{-1}$, and incubated for $30 \mathrm{~min}$ at $37^{\circ} \mathrm{C}$. The cells were recovered by centrifugation $(1400 \mathrm{~g})$, resuspended in $20 \mathrm{ml} 10 \mathrm{~mm}$ - Tris/ $\mathrm{HCl}$ (pH 7.5) buffer containing $1 \%$ (w/v) SDS, $5 \mathrm{~mm}$-EDTA and $200 \mu \mathrm{g}$ proteinase $\mathrm{K} \mathrm{ml}^{-1}$ (Sigma), and incubated for $1 \mathrm{~h}$ at $45^{\circ} \mathrm{C}$. The lysate was extracted twice with equilibrated phenol (Maniatis et al., 1982) and then twice with chloroform/isoamyl alcohol $(24: 1, \mathrm{v} / \mathrm{v})$. The aqueous phases were pooled and adjusted to $0.3 \mathrm{M}$ with respect to sodium acetate $(\mathrm{pH} \mathrm{6.0})$.
Total nucleic acids were precipitated by incubation with 2 vols ethanol at $-20^{\circ} \mathrm{C}$. The nucleic acid pellet was resuspended in $20 \mathrm{ml}$ sodium acetate ( $\mathrm{pH} 6.0)$ and the DNA was sheared by passing the suspension repeatedly through a sterile 23 gauge needle until the viscosity decreased significantly. The suspension was then centrifuged again and the dried pellet resuspended in $0.5 \mathrm{ml} \mathrm{TE}$ buffer $(10 \mathrm{mM}-\mathrm{Tris} / \mathrm{HCl}$, pH 8.0, 1 mM-EDTA) containing $6 \mathrm{~mm}-\mathrm{MgCl}_{2}$. RNAase-free DNAase (37.5 units, Pharmacia LKB) was then added and the mixture incubated for $30 \mathrm{~min}$ at $20^{\circ} \mathrm{C}$. The RNA was precipitated with 2 vols ethanol at $-20^{\circ} \mathrm{C}$, collected by centrifugation $(10000 \mathrm{~g})$ and the dried pellet was resuspended in $50 \mu \mathrm{l}$ sterile distilled water to which $1.5 \mathrm{ml}$ $3 \mathrm{M}$-sodium acetate ( $\mathrm{pH} \mathrm{6.0)}$ ) was added. After incubation for $2 \mathrm{~h}$ at $4{ }^{\circ} \mathrm{C}$ the RNA was collected by centrifugation $(10000 \mathrm{~g})$ and the pellet washed with $0 \cdot 1 \mathrm{M}$-sodium acetate $(\mathrm{pH} 6.0) / 70 \%(\mathrm{v} / \mathrm{v})$ ethanol prior to redissolving in $100 \mu \mathrm{l}$ sterile distilled water. The integrity of the rRNA was determined by electrophoresis in an agarose $(1 \%, w / v)$ mini-gel prepared using TBE buffer $(0.1 \mathrm{M}$-Tris, $83 \mathrm{~mm}$-boric acid, $1 \mathrm{~mm}$ EDTA, pH 8.6) and containing $5 \mu \mathrm{g}$ ethidium bromide $\mathrm{ml}^{-1}$. The concentration of the RNA solution was adjusted to $3 \mu \mathrm{g} \mu \mathrm{l}^{-1}$ and stored at $-70{ }^{\circ} \mathrm{C}$.

$R N A$ sequencing. Eight primers were routinely used to generate sequence data. The sequences and provenance of primers have been given previously (Embley et al., 1988). The method used for sequencing 16S rRNA was that devised by Lane et al. $(1985,1988)$ with slight modifications as follows. The reverse transcription reaction mixture contained 7 units of AMV reverse transcriptase (Stratagene) and $10 \mu \mathrm{Ci}(370 \mathrm{kBq})$ deoxyadenosine $5^{\prime}-\alpha-\left[{ }^{35}\right.$ S $]$ thiotriphosphate (Du Pont; specific activity $1300 \mathrm{Ci} \mathrm{mmol}^{-1}, 48 \cdot 1 \mathrm{TBq} \mathrm{mmol}^{-1}$ ). The nucleotide mixes were prepared using individual ultrapure nucleotide solutions (Pharmacia LKB). Stock mixes were determined empirically to give about 300-350 bases of readable sequence and comprised: A mix, dATP $20 \mu \mathrm{M}$, dCTP dGTP dTTP each at $1.7 \mathrm{mM}$, ddATP $3.2 \mu \mathrm{M}$; C mix, dATP $8.5 \mu \mathrm{M}$, dCTP $0.4 \mathrm{mM}$, dGTP and dTTP each $1.7 \mathrm{mM}$, ddCTP $32.5 \mu \mathrm{M}$; G mix, dATP $8 \mu \mathrm{M}$, dCTP and dTTP each $1.6 \mathrm{mM}$, dGTP $0.4 \mathrm{mM}$, ddGTP $55.8 \mu \mathrm{M}$; T mix, dATP $9 \mu \mathrm{M}$, dCTP and dGTP each $1.8 \mathrm{mM}$, dTTP $0.3 \mathrm{mM}$, ddTTP $67 \mu \mathrm{M}$. The chase mix contained each dNTP at $0.5 \mathrm{mM}$. The products of the sequencing reactions were separated on $55 \mathrm{~cm}$ wedge-shaped $(0.2-0.6 \mathrm{~mm}) 6 \%(\mathrm{w} / \mathrm{v})$ polyacrylamide denaturing (7 M-urea) gels using an LKB Macrophor system

Table 1. Legionella strains included in this study

\begin{tabular}{|c|c|c|c|}
\hline Species & $\begin{array}{c}\text { Strain } \\
\text { designation }\end{array}$ & Source & $\begin{array}{l}\text { GenBank no. of } \\
\text { rRNA sequence }\end{array}$ \\
\hline L. pneumophila & Philadelphia 1 & NCTC $11192^{*}$ & M36023 \\
\hline subsp. pneumophila & Knoxville 1 & NCTC 11286 & M36024 \\
\hline L. pneumophila & Los Angeles 1 & NCTC $11233^{*}$ & M36025 \\
\hline subsp. fraseri & Dallas 1E & NCTC 11405 & M36026 \\
\hline L. erythra & SE $32 \mathrm{~A} \mathrm{C} 8$ & NCTC $11977^{*}$ & M36027 \\
\hline L. hackeliae & Lansing 2 & NCTC $11979^{*}$ & M36028 \\
\hline L. longbeachae & Long Beach 4 & NCTC $11477^{*}$ & M36029 \\
\hline L. spiritensis & Mt St Helens 9 & NCTC $11990^{*}$ & M36030 \\
\hline $\begin{array}{l}\text { L. bozemanii } \\
\text { (Fluoribacter bozemanae) }\end{array}$ & WIGA & NCTC $11368^{*}$ & M36031 \\
\hline $\begin{array}{l}\text { L. micdadei } \\
\text { (Tatlockia micdadei) }\end{array}$ & TATLOCK & NCTC $11371^{*}$ & M36032 \\
\hline
\end{tabular}

* Denotes type strain. 
operated at $50 \mathrm{~W}$ per gel and at $60^{\circ} \mathrm{C}$. Prior to loading the samples, and after $10 \mathrm{~min}$ pre-electrophoresis, sodium acetate ( $3 \mathrm{M}$ in TBE buffer) was added to the lower chamber to give a final concentration of $0.33 \mathrm{M}$ (Brown \& Lund, 1988). After a further $10 \mathrm{~min}$ pre-electrophoresis the samples were loaded and allowed to run until the bromophenol blue tracking dye reached the bottom of the gel (about 4-5 h). Urea was removed by washing (twice, $10 \mathrm{~min}$ ) in a solution comprising $10 \%(\mathrm{v} / \mathrm{v})$ methanol, $10 \%(\mathrm{v} / \mathrm{v})$ acetic acid and $2 \%(\mathrm{w} / \mathrm{v})$ glycerol, followed by a rinse in distilled water. The gel was dried overnight at $80^{\circ} \mathrm{C}$ in a standard oven. Autoradiography was for $24-48$ hours using Fuji RX film.

Data analysis. Sequences were aligned and similarity values calculated using the ALIGN program (Wilbur \& Lipman, 1983) from the DNASTAR suite of programs. The Legionella strains and 13 sequences of Gram-negative bacteria representing the major subgroups of the Proteobacteria were included in these calculations (Dams et al., 1988; Rossau et al., 1988; Stackebrandt et al., 1988; Dewhirst et al., 1989; Dorsch et al., 1989; Weisburg et al., 1989; L. M. Manchester, S. Warwick, W. D. Grant \& T. M. Embley, unpublished data). Positions where a nucleotide could not be determined unambiguously (designated by an IUB uncertainty code) were not included in the alignment. Regions of extreme variation were removed to eliminate noise due to multiple mutations at a single position, and to ensure that only homologous positions were compared. Seven long stretches of sequence (about 1350 bases) were compared (Escherichia coli positions; Brosius $e t$ al., 1978): 2-68, 99-190, 220-840, 846-998, 1004-1023, 1037-1132, 1143-1444. The homology values between the sequences were converted to evolutionary distance or $K_{\text {nuc }}$ values (Hori, 1975; Jukes \& Cantor, 1969). These values were used to produce phylogenetic trees using the algorithm of Fitch \& Margoliash (1967) contained in the PHYLIP 3.22 program (J. Felsenstein, University of Washington). The relationships between the Legionellaceae, Coxiella burnetii, E. coli and Wolbachia persica (as outgroups) were also analysed using the program DNABOOT from the PHYLIP 3.22 program. DNABOOT computes a consensus phylogenetic tree using parsimony and the bootstrap method of sampling sequence data.

\section{Results and Discussion}

The sequencing strategy used in the current investigation generated between 1446 and 1474 bases (about $95 \%$ ) of $16 \mathrm{~S}$ rRNA sequence for the ten strains investigated. The primary sequence data have been deposited in GenBank and assigned the accession numbers shown in Table 1. Fig. 1 shows the matrix of homology values and corresponding $K_{\text {nuc }}$ values obtained from a comparison of approximately 1350 bases of sequence from the legionellae and representatives of the major groupings within the Proteobacteria (Stackebrandt et al., 1988). Fig. 2 is a phylogenetic tree showing the position of the family Legionellaceae. The family forms a subline within the gamma subdivision of the Proteobacteria. This confirms the results of earlier phylogenetic studies which showed the legionellae to be distant relatives of this group (Ludwig \& Stackebrandt, 1983; Weisburg et al., 1989). The relationship is supported by the presence of the signature oligonucleotide CUAACUYYG, which is present at position 510 (E. coli numbering) in all members of the gamma subgroup (Stackebrandt et al.,
1988). The two representatives of the Rickettsiaceae, Coxiella burnetii and Wolbachia persica, showed the closest relationship to the Legionellaceae. The common evolutionary origin of L.pneumophila and C. burnetii, the causal agent of $Q$ fever, was previously established by Weisburg et al. (1989). In this respect it is interesting that some of the bacteria classified as legionellae were originally described as rickettsia-like organisms because of their biological characteristics (Tatlock, 1944; Bozeman et al., 1968).

Fig. 3 shows the internal relationships within the family Legionellaceae based on an analysis of 1350 bases. The tree shown is rooted using Wolbachia persica as an outgroup. The consensus tree obtained using the bootstrap parsimony method had exactly the same topology as this tree. The strains of Legionella show at least $95 \%$ similarity over the 1350 bases of rRNA sequence compared. These values are higher than the similarities (about $90.6 \%$ ) based on approximately 400 bases of sequence which were detected between $L$. micdadei $(T$. micdadei) and L. pneumophila by Fox \& Brown (1989). The discrepancies are due to the fact that the short stretches of sequence which they compared contained a high proportion of the highly variable regions of RNA sequence. In contrast, the data presented here are based upon an analysis of approximately $90 \%$ of the molecule. The representatives of Legionella, including L. bozemanii ( $F$. bozemanae) and $L$. micdadei ( $T$. micdadei), form a cluster which is of a similar depth to the branch between E. coli and Hafnia alvei (Fig. 2). It is, however, much shallower than published values between species of genera such as Mycobacterium (Smida et al., 1988), Pseudomonas (Johnson \& Palleroni, 1989), Saccharopolyspora (Bowen et al., 1989) and Streptomyces (Witt et al., 1989 ). Fig. 3 shows that $L$. bozemanii ( $F$. bozemanae) is closely related $(97.7 \%)$ to $L$. longbeachae and forms a subbranch of the line leading to the subspecies of $L$. pneumophila. This relationship was recovered irrespective of which reference organism, i.e. C. burnetii, E. coli or $W$. persica, was used as an outgroup. It was also recovered in the bootstrap parsimony analysis (not shown). The classification of $L$. bozemanii ( $F$. bozemanae) has been the subject of considerable debate (Garrity et al., 1980; Ludwig \& Stackebrandt, 1983; Brenner, 1986; Brenner et al., 1988). The name L. bozemanii was effectively published for a Legionella-like organism isolated from diseased lung tissue and which exhibited blue-white autofluorescence under long-wave UV light (Brenner et al., 1980). This strain showed less than 13\% DNA relatedness to L. pneumophila (Brenner et al., 1980; Garrity et al., 1980). Subsequently, the new genus Fluoribacter was validly proposed for the same strain (Garrity et al., 1980). Both names currently appear in the Approved Lists of Bacterial Names and it has been left to 


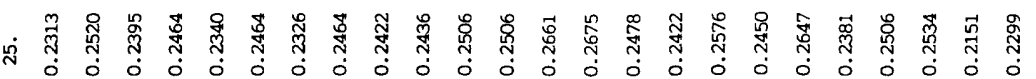

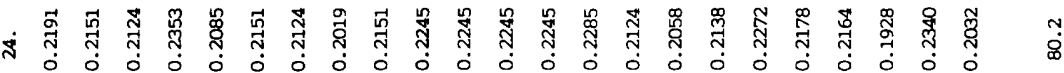

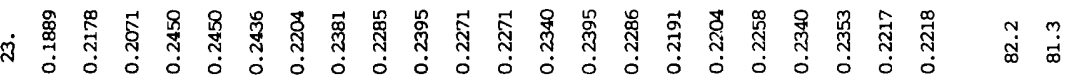

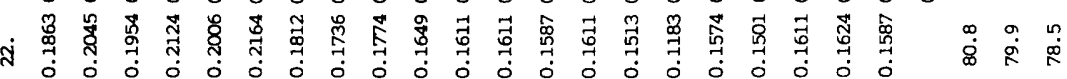

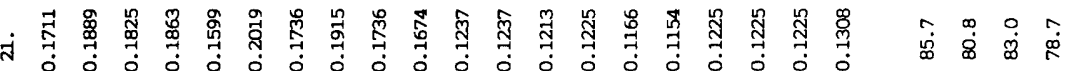

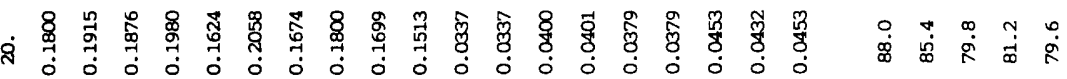

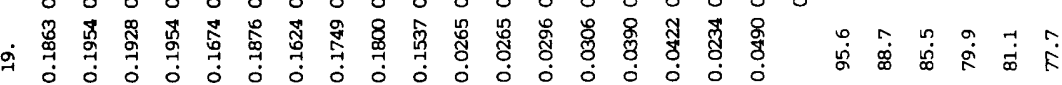

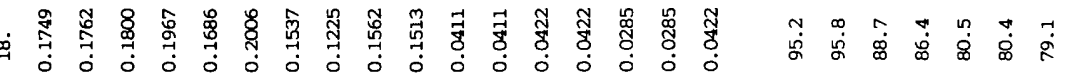

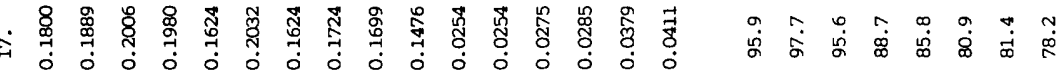

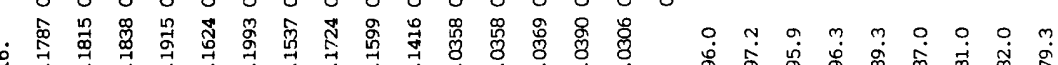

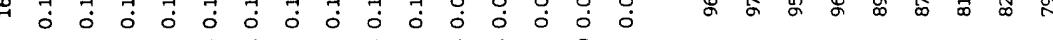

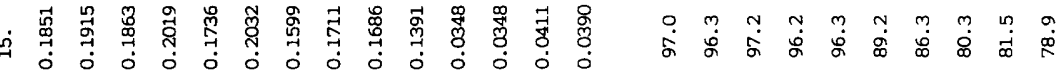

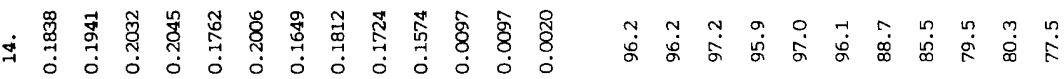

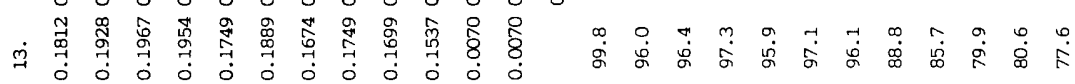

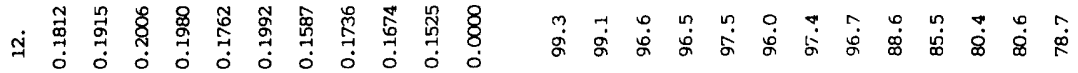

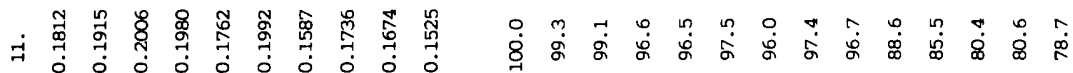

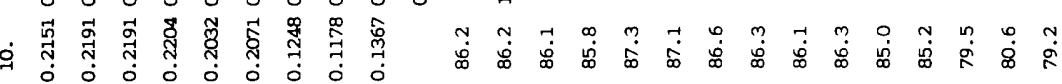

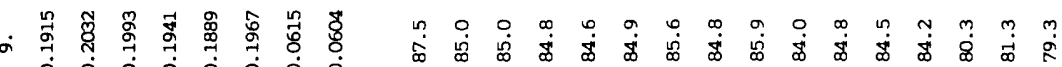
o

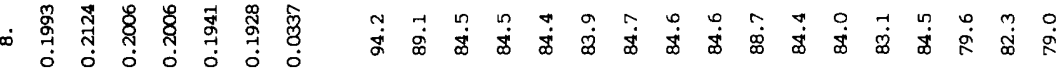

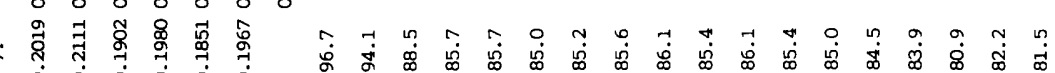

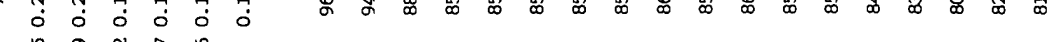

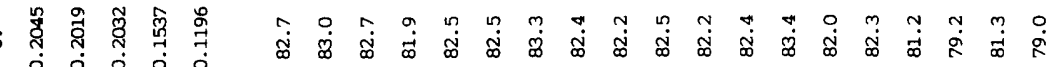

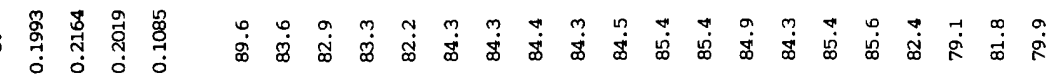

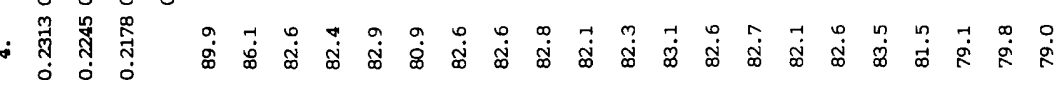

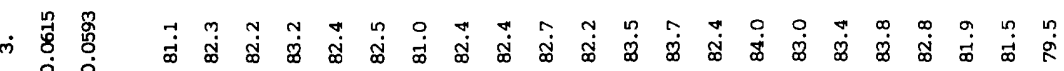

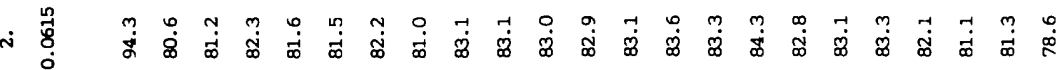

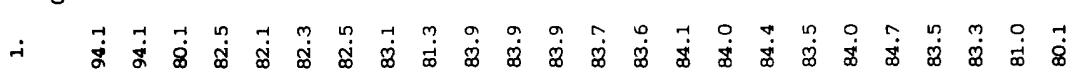

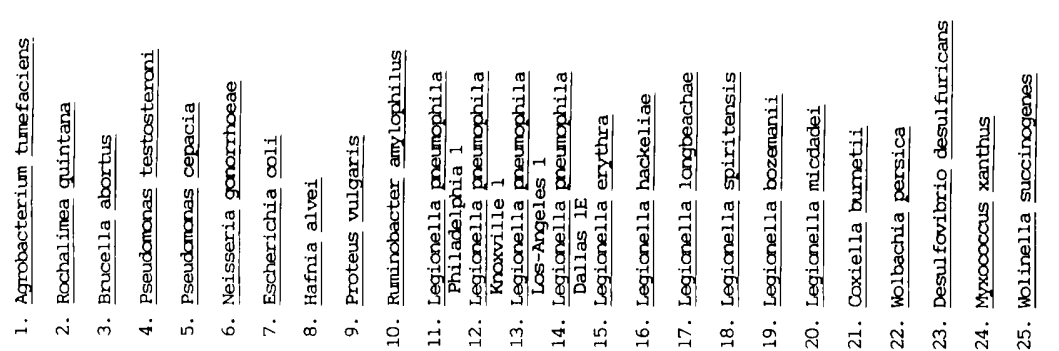




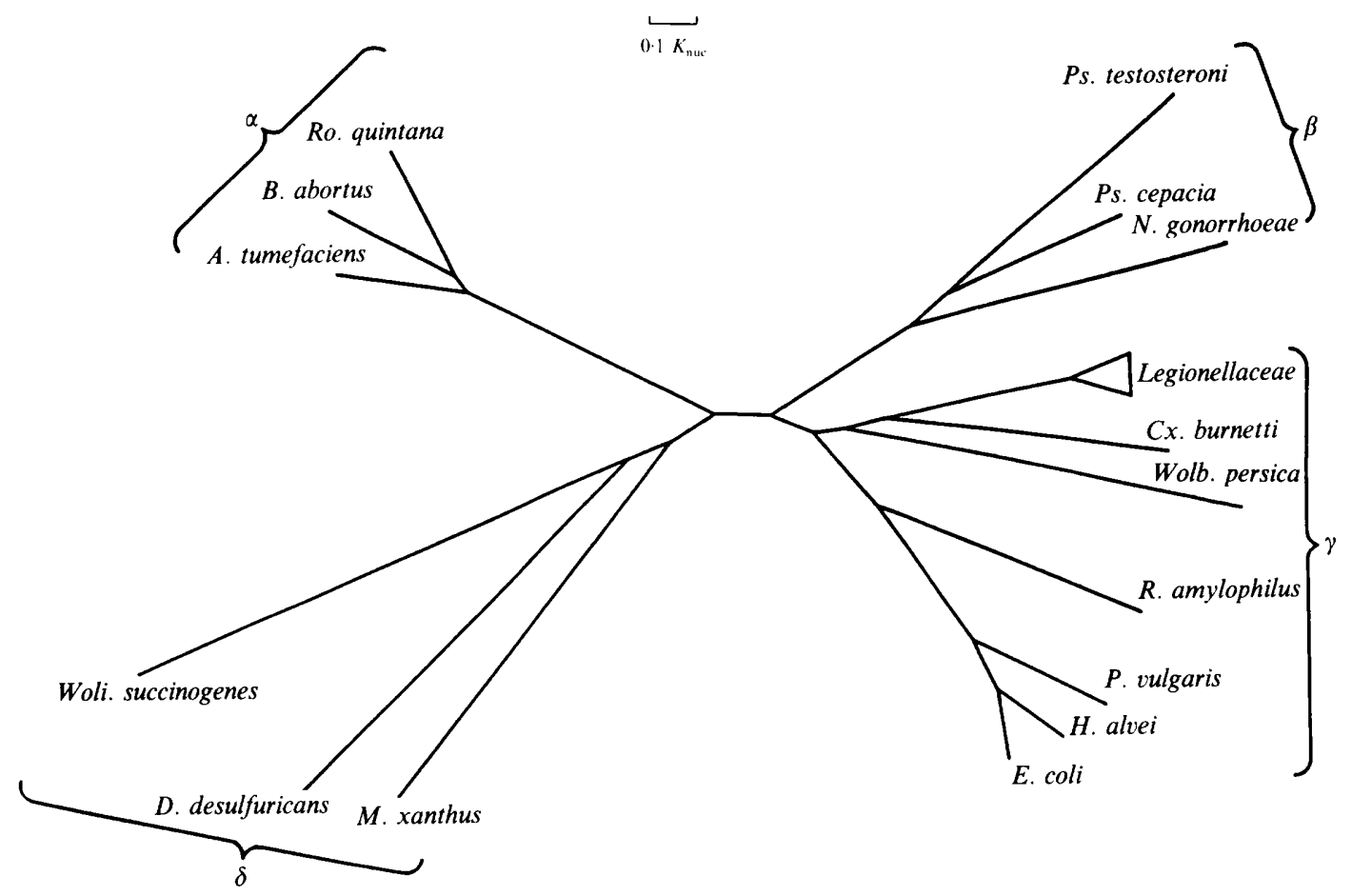

Fig. 2. Unrooted phylogenetic tree showing the position of the family Legionellaceae within the confines of the gamma subdivision of the Proteobacteria. Genera are abbreviated as follows: A., Agrobacterium; B., Brucella ; CX., Coxiella ; D., Desulfovibrio; E., Escherichia; H., Hafnia ; M., Myxococcus; N., Neisseria ; P., Proteus ; Ps., Pseudomonas ; R., Ruminobacter; Ro., Rochalimaea ; Wolb., Wolbachia ; Woli., Wolinella.

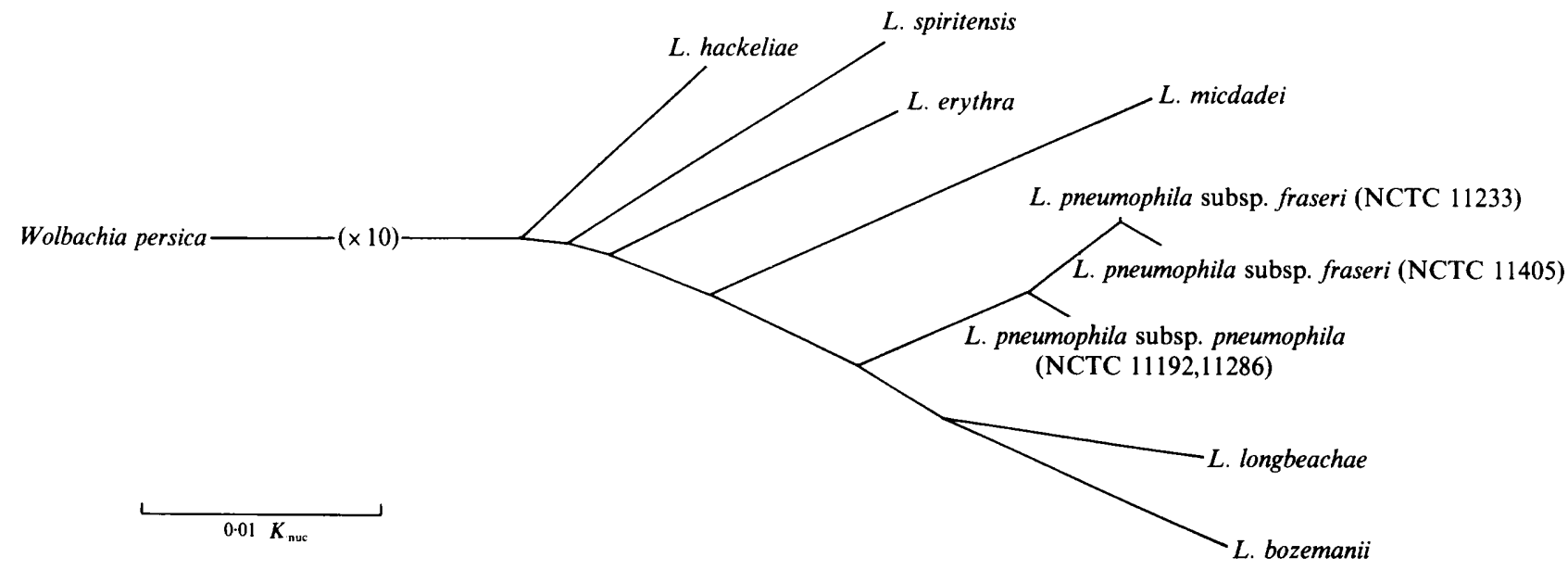

Fig. 3. Phylogenetic tree showing the relationships within the family Legionellaceae. The tree is rooted by reference to Wolbachia persica.

individuals to decide which name they wish to use. A critical argument in the proposal for Fluoribacter bozemanae (Garrity et al., 1980) was a reference to published DNA data for relationships between genera in the family Enterobacteriaceae (Brenner, 1973). This suggested that members of the same genus should show at least $25 \%$ DNA relatedness under optimum condi- tions. However, a number of workers have argued that the genetic relationships between members of the Enterobacteriaceae are uniquely high among eubacterial genera, and are thus an inappropriate model for defining relationships in other taxa (Ludwig \& Stackebrandt, 1983; Brenner, 1986; Brenner et al., 1988). Indeed there are many examples of good phenotypic species which 
show low levels of DNA relatedness in genera such as Streptomyces (Mordarski et al., 1986) and Staphylococcus (Freney et al., 1988). In a further publication, Garrity and coworkers (Brown et al., 1981) transferred two additional species of autofluorescing legionellae to the genus Fluoribacter, as $F$. dumoffii and $F$. gormanii. With the inclusion of these strains the level of DNA relatedness within the genus Fluoribacter dropped to as little as $4 \%$ between some strains (Brown et al., 1981). In contrast, DNA relatedness between some fluoribacters and the non-autofluorescing $L$. longbeachae and $L$. wadsworthii became as high as $17 \%$ and $30 \%$, respectively (Brenner et al., 1985; Brenner, 1986). The results of DNA pairing studies therefore fail to separate Fluoribacter from non-autofluorescing strains of Legionella (Brenner et al., 1985). In our investigation, L. bozemanii (F. bozemanae) clearly falls within the phylogenetic radiation defined by non-autofluorescent species of Legionella.

The genus Tatlockia was proposed (Brown et al., 1981) for a strain previously classified as Legionella micdadei (Hébert et al., 1980b). The main rationale behind this proposal was the inability to detect any DNA homology between this strain and L. pneumophila (Brown et al., 1981). Subsequent work has shown that $L$. micdadei ( $T$. micdadei) shows moderate levels of relatedness to $L$. maceachernii ( $23 \%)$ and L. spiritensis $(16 \%)$ (Brenner et al., 1985). In the current investigation $L$. micdadei ( $T$. micdadei) showed $95-96 \%$ similarity in rRNA sequence (over 1350 bases) to strains of $L$. pneumophila, $L$. spiritensis, L. erythra, L. hackeliae and $L$. bozemanii $(F$. bozemanae) (Fig. 1). In addition, L. micdadei was found to lie within the confines of the radiation defined by Legionella in all of the phylogenetic trees constructed from our data.

The strains of $L$. pneumophila were recovered as two closely related ( $>99 \%$ similarity) clusters which represented the two subspecies pneumophila and fraseri. The two strains of $L$. pneumophila subsp. pneumophila were indistinguishable for the entire 1470 bases of $16 \mathrm{~S}$ rRNA sequence considered. The two strains of $L$. pneumophila subsp. fraseri differed at only two positions over 1470 bases. The two subspecies could be differentiated by seven base changes and a single deletion. All of the $L$. pneumophila isolates had a characteristic oligonucleotide UUAUAUGAAAAUAA at position 837 (E. coli numbering), which served to differentiate them from the other legionellae. L. erythra, L. spiritensis and L. hackeliae defined the periphery of the family Legionellaceae in all of the phylogenetic trees. However, the juxtaposition of the three species showed slight variation depending upon the choice of outgroup. Very little can therefore be concluded concerning their specific relationships.

It has recently been suggested that the integrated use of phylogenetic and phenotypic characters is necessary for the delineation of bacterial taxa at all levels (Murray et al., 1990). L. bozemanii ( $F$. bozemanae) and L. micdadei (T. micdadei) can be distinguished from other species of Legionella using detailed analysis of carbohydrate composition (Fox et al., 1984, 1990), and quantitative fatty acid and ubiquinone composition (Karr et al., 1982; Lambert \& Moss, 1989). However, the spectrum of variation of these features is of the same magnitude as found between other species of Legionella and is therefore insufficient to justify separate genera for these strains (Brenner et al., 1984; Lambert \& Moss, 1989; Fox et al., 1990). The major evidence for the separation of the Legionellaceae into different genera stems from the interpretation of the low DNA pairing values which are obtained between some species (Garrity et al., 1980; Brown et al., 1981; Brenner et al., 1985). At the moment these cannot be consistently interpreted to recognize phenotypically coherent groups. In contrast to the low DNA pairing values published for legionellae, all of the species examined in the present study were found to be highly related at the rRNA sequence level. Furthermore, $L$. bozemanii ( $F$. bozemanae) and $L$. micdadei ( $T$. micdadei) clearly fall within the radiation defined by Legionella. It is therefore phylogenetically invalid to place these species in separate genera. In the absence of compelling phenotypic differences (Brenner, 1986; Murray et al., 1990) we conclude that all of the species examined in the current investigation should be regarded as members of the genus Legionella (Brenner et al., 1980; Hébert et al., 1980b; Morris et al., 1980).

The authors would like to thank Dr T. Harrison for help and advice on the choice of strains. This work was supported in part by a research grant from the PCFC Selective Research Initiative to T.M.E. and S.W.

\section{References}

Bowen, T., Stackebrandt, E., Dorsch, M. \& Embley, T. M. (1989). The phylogeny of Amycolata autotrophica, Kibdelosporangium aridum and Saccharothrix australiensis. Journal of General Microbiology 135, 2529-2536.

Bozeman, F. M., Humphries, J. W .\& Campbell. J. M. (1968). A new group of rickettsia-like agents recovered from guinea pigs. Acta Virologia 12, 87-93.

Brenner, D. J. (1973). Deoxyribonucleic acid reassociation in the taxonomy of enteric bacteria. International Journal of Systematic Bacteriology 23, 298-307.

Brenner, D. J. (1986). Classification of Legionellaceae: current status and remaining questions. Israel Journal of Medical Sciences 22, 620 632.

Brenner, D. J., Steigerwalt, A. G. \& McDade. J. E. (1979). Classification of the Legionnaires' disease bacterium: Legionella pneumophila, genus novum, species nova, of the family Legionellaceae, familia nova. Annals of Internal Medicine 90, 656-658.

Brenner, D. J., Steigerwalt, A. G., Gorman, G. W., Weaver, R. E., Feeley, J. C., Cordes, L. G., Wilkinson, H. W., Patton, C., Thomason, B. M. \& Sasseville, K. R. L. (1980). Legionella 
bozemanii sp. nov. and Legionella dumoffii sp. nov. : classification of two additional species of Legionella associated with human pneumonia. Current Microbiology 4, 111-116.

Brenner, D. J., Feeley, J. C. \& Weaver, R. E. (1984). Family Legionellaceae. In Bergey's Manual of Systematic Bacteriology, vol. I, pp. 279-288. Edited by N. R. Krieg \& J. G. Holt. Baltimore: Williams \& Wilkins.

Brenner, D. J., Steigerwalt, A. G., Gorman, G. W., Wilkinson, H. W., BibB, W. F., Hackel, M., Tyndall, R. L., Campbell, J., Feeley, J. C., Thacker, W. L., Skaliy, P., Martin, W. T., Brake, B. J., Fields, B. S., McEachern, H. V. \& Corcoran, L. K. (1985). Ten new species of Legionella. International Journal of Systematic Bacteriology 35, 50-59.

Brenner, D. J., Steigerwalt, A. G., Epple, P., BibB, W. F., McKinney, R. M., Starnes, R. W., Colville, J. M., Selander, R. K., Edelstein, P. H. \& Moss, C. W. (1988). Legionella pneumophila serogroup Lansing 3 isolated from a patient with fatal pneumonia, and descriptions of $L$. pneumophila subsp. pneumophila subsp. nov., $L$. pneumophila subsp. fraseri subsp. nov., and $L$. pneumophila subsp. pascullei subsp. nov. Journal of Clinical Microbiology 26, 1695-1703.

Brosius, J., Palmer, M. L., Kennedy, P. J. \& Noller, H. F. (1978). Complete nucleotide sequence of a $16 \mathrm{~S}$ ribosomal RNA gene from Escherichia coli. Proceedings of the National Academy of Sciences of the United States of America 75, 4801-4805.

Brown, A., Garrity, G. M. \& Vickers, R. M. (1981). Fluoribacter dumoffii (Brenner et al.) comb. nov. and Fluoribacter gormanil (Morris et al.) comb. nov. International Journal of Systematic Bacteriology 31, 111-115.

Brown, N. L. \& LUND, P. A. (1988). DNA sequencing. Methods in Microbiology 21, 253-304.

Dams, E., Hendriks, L., Van de Peer, Y., Neefs, J.-M., Smits, G., VANDENBEMPT, I. \& DE WACHER, R. (1988). Compilation of small ribosomal subunit RNA sequences. Nucleic Acids Research 16, Supplement: $r 87-r 175$.

Dewhirst, F. E., Paster, B. J. \& Bright, P. L. (1989). Chromobacterium, Eikenella, Kingella, Neisseria, Simonsiella, and Vitreoscilla species comprise a major branch of the beta group Proteobacteria by $16 \mathrm{~S}$ ribosomal ribonucleic acid sequence comparison: transfer of Eikenella and Simonsiella to the family Neisseriaceae (emend.). International Journal of Systematic Bacteriology 39, 258-266.

Dorsch, M., Moreno, E. \& Stackebrandt, E. (1989). Nucleotide sequence of the 16S rRNA from Brucella abortus. Nucleic Acids Research 17, 1765.

Embley, T. M., Smida, J. \& Stackebrandt, E. (1988). Reverse transcriptase sequencing of $16 \mathrm{~S}$ ribosomal RNA from Faenia rectivirgula, Pseudonocardia thermophila and Saccharopolyspora hirsuta, three wall type IV actinomycetes which lack mycolic acids. Journal of General Microbiology 134, 961-966.

Fitch, W. M. \& Margoliash, E. (1967). Construction of phylogenetic trees: a method based on mutational distances as estimated from cytochrome $c$ sequences is of general applicability. Science 155, 279284.

Fox, K. F. \& Brown A. (1989). Partial sequence analysis of the 16SrRNA of legionellae: taxonomic implications. Systematic and Applied Microbiology 11, 135-139.

Fox, A., Lau, P. Y., Brown. A., Morgan, S. L., Zhu, Z.-T., Lena, M. \& WALLA, M. D. (1984). Capillary gas chromatographic analysis of carbohydrates of Legionella pneumophila and other members of the family Legionellaceae. Journal of Clinical Microbiology 19, 326332.

Fox, A., Rogers, J. C., Fox, K. F., Schnitzer, G., Morgan, S. L., Brown, A. \& Aono, R. (1990). Chemotaxonomic differentiation of legionellae by detection and characterisation of aminodideoxyhexoses and other unique sugars using gas-chromatography-mass spectrometry. Journal of Clinical Microbiology 28, 546552.

Freney, J., Brun, Y., Bes, M., Meugnier, H., Grimont, F., Grimont, P. A. D., Nervi, C. \& Fleurette, J. (1988). Staphylococcus lugdunensis sp. nov. and Staphylococcus schleiferi sp. nov., two species from human clinical specimens. International Journal of Systematic Bacteriology 38, 168-172.
Garrity, G. M., Brown, A. \& Vickers, R. M. (1980). Tatlockia and Fluoribacter: two new genera of organisms resembling Legionella pneumophila. International Journal of Systematic Bacteriology 30, 609614.

HéberT, G. A., Moss, C. W., McDougal, L. K., Bozeman, F. M., MCKINNEY, R. M. \& BRENNER, D. J. (1980a). The rickettsia-like organisms TATLOCK (1943) and HEBA (1959); bacteria phenotypically similar to but genetically distinct from Legionella pneumophila and the WIGA bacterium. Annals of Internal Medicine 92, $45-52$.

Hébert, G. A., Steigerwalt, A. G. \& Brenner, D. J. (1980 $b$ ). Legionella micdadei species nova: classification of a third species of Legionella associated with human pneumonia. Current Microbiology 3, 255-257.

HORI, I. (1975). Evolution of 5S rRNA. Journal of Molecular Evolution 7, 75-86.

Johnson, J. L \& Palleroni, N. J. (1989). Deoxyribonucleic acid similarities among Pseudomonas species. International Journal of Systematic Bacteriology 39, 230-235.

JUKES, T. H. \& CANTOR, C. R. (1969). Evolution of protein molecules. In Mammalian Protein Metabolism. pp. 21-132. Edited by H. N. Munro. New York: Academic Press.

KARR, D. E, BIBB, W. F. \& Moss, C. W. (1982). Isoprenoid quinones of the genus Legionella. Journal of Clinical Microbiology 15, 1044-1048.

LAMBERT, M. A. \& Moss, C. W. (1989). Cellular fatty acid compositions and isoprenoid quinone contents of 23 Legionella species. Journal of Clinical Microbiology 27, 465-473.

Lane, D. J., Pace, B., Olsen, G. J., Stahl, D. A., Sogin, M. L. \& PACE, N. R. (1985). Rapid determination of 16S ribosomal RNA sequences for phylogenetic analyses. Proceedings of the National Academy of Sciences of the United States of America 82, 69556959.

LANE, D. J., Field, K. G ., Olsen, G. J. \& PaCe, N. R. (1988). Reverse transcriptase sequencing of ribosomal RNA for phylogenetic analysis. Methods in Enzymology 167, 138-141.

LUDWIG, W. \& STACKEBRANDT, E. (1983). A phylogenetic analysis of Legionella. Archives of Microbiology 135, 45-50.

Maniatis, T., Fritsch, E. F. \& Sambrook, J. (1982). In Molecular Cloning: a Laboratory Manual, p. 438. Cold Spring Harbor, NY: Cold Spring Harbor Laboratory.

Mordarski, M., Goodfellow, M., Williams, S. T. \& SNeath, P. H. A. (1986). Evaluation of species groups in the genus Streptomyces. In Biological, Biochemical and Biomedical Aspects of Actinomycetes, pp. 517-526. Edited by G. Szabo, S. Biro \& M. Goodfellow. Budapest: Akademiai Kiado.

Morris, G. K., Steigerwalt, A. G., Feeley, J. C., Wong, E. S., Martin, W. T., Patton, C. M., \& Brenner, D. J. (1980). Legionella gormanii sp. nov. Journal of Clinical Microbiology 12, 718-721.

Murray, R. G. E., Brenner, D. J., Colwell, R. R., De Vos, P., Goodfellow, M., Grimont, P. A. D., Pfennig, N., StackeBRANDT, E. \& ZaVarzin, G. A. (1990). Report of the ad hoc committee on approaches to taxonomy within the Proteobacteria. International Journal of Systematic Bacteriology 40, 213-215.

Rossau, R., Heyndrickx, L. \& Van Heuverswyn, H. (1988). Nucleotide sequence of a $16 \mathrm{~S}$ ribosomal RNA gene from Neisseria gonorrhoeae. Nucleic Acids Research 16, 6227.

SAUNDERS, N. A. \& GRANT, M. E. (1984). Elastin biosynthesis in chick embryo arteries. Biochemical Journal 221, 393-400.

Smida, J., Kazda, J. \& StackebrandT, E. (1988). Molecular-genetic evidence for the relationship of Mycobacterium leprae to slowgrowing pathogenic mycobacteria. International Journal of Leprosy 56, 449-454.

Stackebrandt, E., Murray, R. G. E. \& TrüPer, H. G. (1988). Proteobacteria classis nov., a name for the phylogenetic taxon that includes the 'purple bacteria and their relatives'. International Journal of Systematic Bacteriology 38, 321-325.

TATLOCK, H. (1944). A rickettsia-like organism recovered from guinea pigs. Proceedings of the Society for Experimental Biology and Medicine 57, 95-99.

Vesey, G., Dennis, P. J., LeE., J. V. \& West, A. A. (1988). Further development of simple tests to differentiate the legionellas. Journal of Applied Bacteriology 65, 339-345. 
Weisberg, W. G., Dobson, M. E., Samuel, J. E., Dasch, G. A., Mallavia, L. P., Baca, O., Mandelco, L., Sechrest, J. E., Weiss, E. \& WOESE, C. R. (1989). Phylogenetic diversity of the Rickettsiae. Journal of Bacteriology 171, 4202-4206.

WILBUR, W. J. \& LIPMAN, D. J. (1983). Rapid similarity searches of nucleic acid and protein data banks. Proceedings of the National Academy of Sciences of the United States of America 80, 726-730.
WitT, D., Liesack, W. \& Stackebrandt, E. (1989). Identification of streptomycetes by $16 \mathrm{~S}$ rRNA sequences and oligonucleotide probes. In Recent Advances in Microbial Ecology, pp. 679-684. Edited by T. Hattori, Y. Ishida, Y. Maruyama, R. Morita \& A. Uchida. Tokyo: Japan Scientific Society Press.

WoEse, C. R. (1987). Bacterial evolution. Microbiological Reviews 51, 221-271. 